\title{
Portocaval shunt and its Implications for Liver Transplantation: An Integrative Literature Review
}

\author{
Olival Cirilo Lucena da Fonseca Neto ${ }^{1}$ (D), Maria Eduarda de Freitas Mesquita do Nascimento ${ }^{2}$ (D), \\ Lucas Loiola Ponte Albuquerque Ribeiro ${ }^{3}$ (i)
}

1. Hospital Universitário Oswaldo Cruz RớR Serviço de Cirurgia Geral e Transplante de Fígado, Recife (PE), Brasil.

2. Universidade de Pernambuco Rór Recife (PE), Brasil.

3. Universidade de Fortaleza Ró -

Fortaleza (CE), Brasil.

doi https://doi.org/10.53855/bjt.v25i1.426_en

Correspondence author:

olivallucena@gmail.com

Section Editor

Ilka Boin

Received

Dez. 14, 2021

Approved

Jan. 17, 2022

Conflict of interest

Nothing to declare.

How to Cite

Fonseca Neto OCL, Nascimento MEFM, Ribeiro LLPA. Portocaval shunt and its Implications for LiverTransplantation: An Integrative Literature Review. BJT.2022; 25(01): e0322. https://doi.org/10.53855/bjt. v25i1.426_en

eISSN

2764-1589

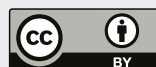

\begin{abstract}
Introduction: Portal vein clamping can generate splanchnic venous congestion and increase portal hypertension, causing release of inflammatory mediators in liver transplantation. The venous bypass technique was developed at the beginning to avoid congestion. In 1968, the piggyback technique was described, and in 1993 and 1995, the temporary portocaval shunt (TPCS) was described as an alternative to preserve the flow of the vena cava and the intraoperative portal system. With the expansion of the number of living transplants, an adaptation of the anastomosis, or temporary hemi portocaval shunt (THPCS) was developed. Objective:This review aimed to analyze the literature found in the TPCS and THPCS databases in adult liver transplantation. Methods: Integrative review carried out through searches in PubMed, Online Scientific Electronic Library (SciELO) and Literatura Latino-Americana e do Caribe em Ciências da Saúde (Lilacs) databases, with 15 articles published in the last 12 years (2010-2021) being selected, after applying criteria defined by the authors and including three works for historical reference. Results: The increase in surgery time does not seem to be a significant disadvantage that justifies contraindication to the use of portocaval anastomosis during the procedure. In transplantation, there is an indication that the TPCS improves hemodynamic stability, with reduced infusion of packed red blood cells and platelets. Data on postoperative levels of aminotransferase, aspartate aminotransferase, and international normalized index were conflicting, with improvement in renal function as assessed by creatinine measurement. The studies demonstrate a relationship between TPCS and a decrease in hospital stay. It was not possible to reach a conclusion regarding the impacts on survival after transplantation. THPCS appears to be effective in decreasing portal flow, serving its purpose of preventing hyperflow, however it does not appear to be an absolute guarantee of preventing complications. The biggest perceived limitation was the heterogeneity of the studies included in this review. Conclusion: The developed studies point to benefits in hemodynamic stability and postoperative renal function and shorter hospital stay. It was not possible to conclude about the impact of the technique on liver injury, overall survival or graft survival, due to divergences in the literature.
\end{abstract}

Descriptors: Surgical Portocaval Diversion; Liver Transplant; Vena Cavas.

\section{INTRODUCTION}

During the anhepatic phase of liver transplantation, clamping the portal vein of the recipient's liver can generate splanchnic venous congestion (anatomy depicted in Fig. 1) and increase portal hypertension, which leads to intestinal edema and mucosal barrier dysfunction, with bacterial translocation, endotoxemia and secretion of inflammatory 
mediators. ${ }^{1-3} \mathrm{After}$ declamping the portal vein, these factors are released into the circulation, which can cause systemic vasodilation, hypotension, and ischemia-reperfusion syndrome and, eventually, primary graft dysfunction. ${ }^{2,3}$

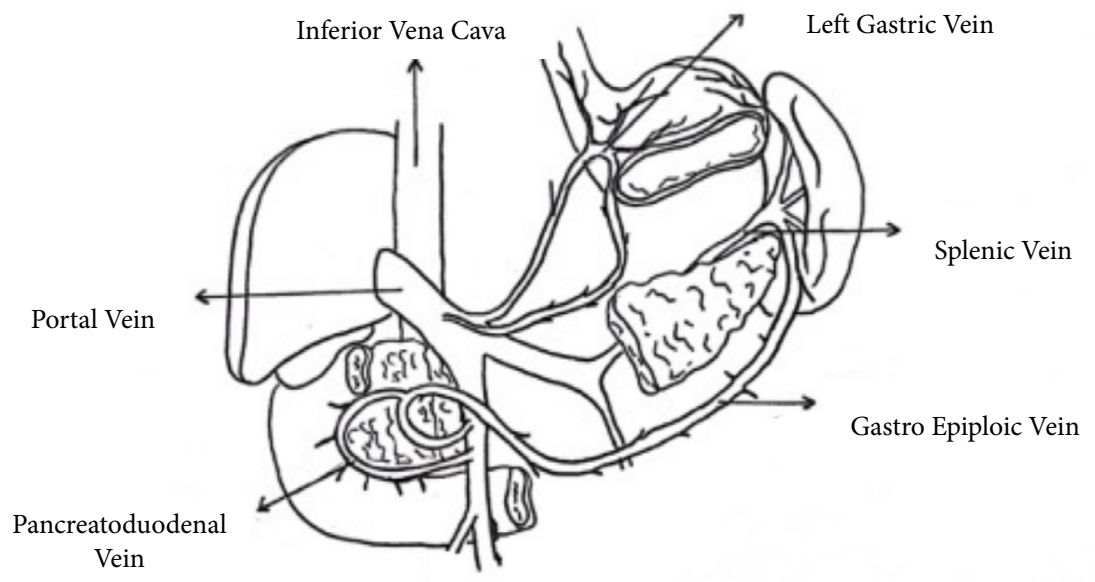

Figure 1. Representation of the normal anatomy of the portal system, demonstrating the interconnection between hepatic, splenic and intestinal venous drainage.

Therefore, early in the history of transplantation, the technique of venous bypass was developed to avoid splanchnic and systemic venous congestion and other deleterious effects caused by clamping the portal vein during the anhepatic phase. In 1968 , Calne and Williams described liver transplantation with preservation of the inferior vena cava, a technique that improves venous return to the heart and reduces infradiaphragmatic congestion by preserving the retrohepatic inferior vena cava, improving hemodynamic stability. ${ }^{4-9}$ In association with this technique, in 1993 and 1995, respectively, Belghiti et al. ${ }^{8}$ and Tzakis et al. ${ }^{10}$ popularized the temporary portocaval shunt (TPCS) associated with the piggyback technique, as a way of preserving the flow of the vena cava and portal system throughout the procedure, especially in patients without developed collateral circulation, as in cases of acute liver failure, as shown in Fig. $2 .^{8-10}$

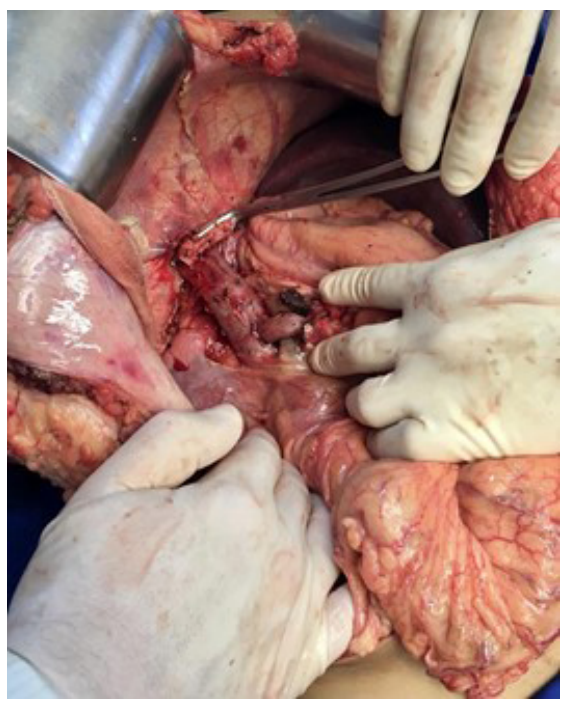

Figure 2. Intraoperative image of a portocaval anastomosis during liver transplantation.

Due to the difficulty of finding enough donors and the growing demand for transplants, living-donor transplantation has gained more and more space. ${ }^{10-12}$ In this context, graft weight has become a concern, due to the risk of developing the smallfor-size syndrome, the cause of which has been related to excessive portal flow. ${ }^{11,12}$ Therefore, in order to avoid injury due to elevation of the portal flow, an adaptation of the portocaval anastomosis technique was developed to modulate the flow in living 
transplants, the so-called temporary hemiportocaval shunt (THPCS), or hemiportocaval anastomosis. ${ }^{5,11,13}$ Other techniques that can be used to modulate flow are splenectomy, splenic artery ligation, and splenorenal shunt. ${ }^{10,12}$

Despite this, the benefits of TPCS remain controversial, with studies showing conflicting results. ${ }^{1,3,14,15}$ The objective of this review, therefore, was to analyze the literature found in the databases on TPCS and THPCS in liver transplantation in adults.

\section{METHODOLOGY}

This is an integrative review of the available literature on the implications of the TPCS technique in liver transplantation. A search was performed in PubMed, Online Scientific Electronic Library (SciELO) and Latin American and Caribbean Literature on Health Sciences (Lilacs) databases, with the descriptors anastomose portocava and transplante de figado, and their equivalents in English, applying the filter humanos.In the PubMed database, 63 results were found for the given period (2010-2021), and, after reading the titles and abstracts, articles that did not directly address liver transplantation, studies with animals, pediatric studies and an article that did not directly address liver transplantation were excluded. described the technique as a bridge to transplantation, and not as an intraoperative approach during liver transplantation. No articles were found in the SciELO and Lilacs databases.

In addition, a search was performed for shunt hemiportocava and its equivalent in English in the aforementioned databases, with seven results being found in the PubMed database, four of which were excluded, three for not directly addressing hemiportocaval shunt and one for duplication. No articles were found in the SciELO and Lilacs databases. In addition, three works were manually included, as they were the publications that first described the TPCS technique in liver transplantation, for historical purposes..

In the end, 18 articles were included in this integrative review, with the selection process described in Fig. 3.

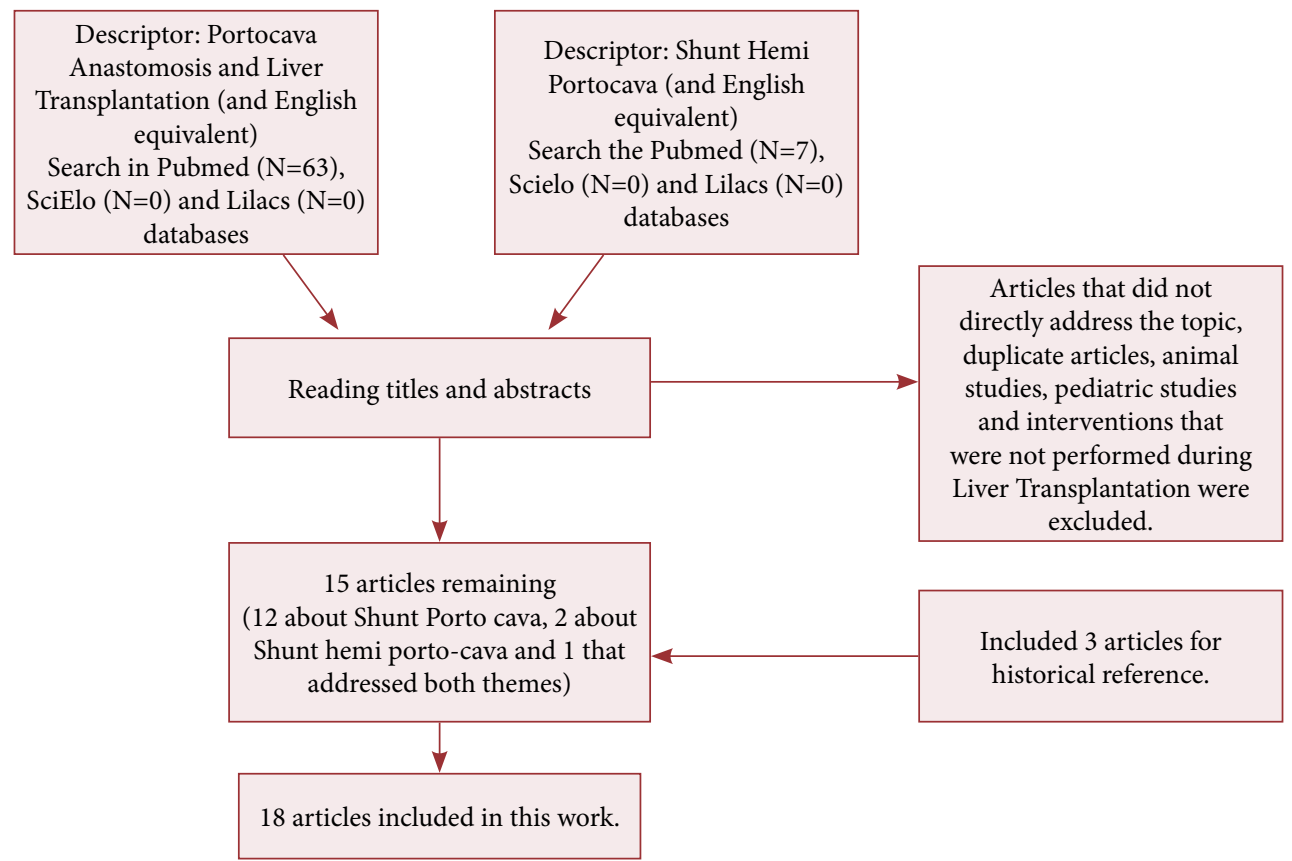

Figure 3. Representation of the article selection process for this review.

To analyze the use of temporary portocaval anastomosis in liver transplantation, the following aspects were analyzed: duration of surgery; hemodynamic stability, assessed by the number of packed red blood cells and fresh frozen plasma, as well as the use of vasopressors; postoperative infection; hepatic injury, evaluated by means of postoperative alanine aminotransferase (ALT), aspartate aminotransferase (AST) and international normalized index (INR); renal function, assessed by serum creatinine; length of stay; and overall and graft survival. 


\section{RESULTS AND DISCUSSION}

\section{Surgery time}

The increase in surgery time for performing the TPCS was a concern raised by some authors, however, in the meta-analysis carried out by Pratschke et al., ${ }^{14}$ the procedure time proved to be shorter than that of the group without TPCS. The same was seen in a retrospective study of Nacif et al., ${ }^{16}$ while other authors reported that there was no difference. ${ }^{2,715,17}$ According to Belghiti et al., ${ }^{8}$ the average time to perform the shunt is 9 minutes, and for Faitot et al. ${ }^{9}$ the time varies between 5 and 15 minutes.

Only two studies, by Rayar et al. ${ }^{3}$ and Weniger et al., ${ }^{18}$ found an increase in surgical time in the group undergoing TPCS. In cases where there was an increase in the anhepatic phase in the TPCS group, as in the prospective study conducted by Son et al., ${ }^{17}$ there was no impact on anesthetic sensitivity or postoperative cognitive function.

Therefore, the increase in surgery time does not seem to be a significant disadvantage that justifies contraindication to the use of portocaval anastomosis during liver transplantation.

\section{Hemodynamic stability}

In the meta-analysis included in this study, a significant reduction in the number of transfusions of packed red blood cells was identified in the group undergoing TPCS, which may suggest better hemodynamic stability due to lower volume loss, ${ }^{7}$ however, there was no difference in the transfusion of fresh frozen plasma between patients undergoing TPCS and those not undergoing.?

Pratschke et al., ${ }^{14}$ in their retrospective analysis, found a significant reduction in the use of vasopressors in patients undergoing TPCS, while the work of Ghinolfi et al. ${ }^{15}$ found a non-significant trend towards greater use of vasopressors in patients not undergoing shunt, who received higher doses of phenylephrine, but with no significant difference in the necessary doses of epinephrine and norepinephrine. However, Weniger et al. ${ }^{18}$ found no differences in the use of norepinephrine between the groups.

Evaluating the available data, there is an indication that the performance of TPCS during liver transplantation improves the hemodynamic stability of patients, but there is still no consensus in the literature on this.

\section{Postoperative infection}

Portal vein clamping during the procedure was associated with increased intestinal edema and bacterial translocation..$^{1,3,7,14}$ Despite the pathophysiology described in several studies, only one study investigated whether the described translocation resulted in an increase in postoperative infection, comparing groups with TPCS and use of meropenem, TPCS and use of meropenem plus vancomycin and the group without TPCS. ${ }^{18}$

The hypothesis, however, proved to be null, with no difference between the three groups in terms of the general incidence of infections and gram-negative infections, with only a tendency towards greater gram-positive infections in the TPCS and use of meropenem. This data, added to the finding of better survival in the TPCS group and the use of meropenem and vancomycin, seems to suggest that the inclusion of vancomycin in antibiotic prophylaxis would be beneficial. ${ }^{18}$

\section{Liver injury}

Several studies have analyzed liver damage through post-transplant ALT and AST measurements. Two studies identified lower levels of AST in patients undergoing TPCS (in one of them, a non-statistically significant reduction was seen), suggesting less aggression to hepatocytes, however there was no difference in ALT levels, ${ }^{7,15}$ while another study found a reduction in both. ${ }^{14}$ Regarding prothrombin times and INR, the two articles that analyzed these variables had conflicting results, with one of them suggesting improvement in cases in which TPCS was performed, and the other with no difference between the groups. ${ }^{3,15}$

\section{Kidney function}

The meta-analysis by Pratschke et al. ${ }^{7}$ found a decrease in postoperative creatinine values in patients undergoing TPCS compared to controls in all included studies, except for one, which did not find significant variations. In the work by Ghinolfi et al., ${ }^{15}$ the 
benefit in creatinine values was only significant in the first $72 \mathrm{~h}$ after the procedure, and after that period the values of both groups became similar.

Based on these data, TPCS appears to improve renal perfusion, as suggested by pathophysiology, leading to better postoperative renal function.

\section{Hospital stay time}

The two meta-analyses included in this study identified shorter length of stay in the intensive care unit and shorter length of stay in patients undergoing TPCS. In one of them, the difference was statistically significant.5,7 in the works of Rayar et al. ${ }^{3}$ and Ghinolfi et al., ${ }^{15}$ however, they found dissonant results, with no difference in the length of hospital stay between patients submitted or not to temporary shunt, both being retrospective analyses. As the meta-analyses have a higher level of evidence and more accurate methodological analysis, it is believed that the TPCS may be related to the reduction in hospitalization time.

\section{Graft survival and overall survival}

Two studies found no difference between overall and graft survival comparing groups with and without TPCS, ${ }^{1,3}$ however, two other studies found better overall survival among patients over 70 years of age when undergoing TPCS.,16

Analyzing graft survival at three months, two studies demonstrated better survival in patients undergoing temporary portocaval anastomosis. ${ }^{3,5}$ This benefit seems to be present especially in grafts from extended criteria donors, who seem to be especially susceptible to ischemia-reperfusion syndrome. ${ }^{3}$

As the studies showed conflicting results, it was not yet possible to conclude on the relationship of portocaval anastomosis or on survival after liver transplantation.

\section{Hemiportocava in living donor transplantation}

THPCS appears to be effective in decreasing portal flow, serving its purpose of preventing hyperflow, the main component of the small-for-size syndrome, which manifests as cholestasis, coagulopathy, portal hypertension, and encephalopathy, which can lead to death. ${ }^{11,13}$ However, it does not seem to be an absolute guarantee in preventing the syndrome, which has been identified even among patients undergoing THPCS. ${ }^{11}$

The main complication is related to excessive flow reduction, causing the so-called portal steal syndrome, which manifests as encephalopathy and graft regeneration failure. ${ }^{11,12}$ The main risk factor for its development is the existence of large, unknown spontaneous shunts, but it can also be caused by the constructed shunt. ${ }^{12}$

To avoid extremes and ensure adequate flow, the anastomosis diameter and the vena cava pressure gradient were proposed as parameters, but they still lack validation and standardization. ${ }^{11,12}$ The need to close the shunt is controversial. Some authors encourage individual case assessment and argue against the need to routinely close the shunt in all patients, ${ }^{11}$ however, other authors recommend shunt closure to prevent encephalopathy. ${ }^{13}$ In any case, it is necessary to take into account that there is a possibility of spontaneous shunt closure, with a study describing such an occurrence in $2 / 3$ of patients. ${ }^{13}$

\section{Limitations}

The articles analyzed included heterogeneous populations and different methodologies, most of them retrospective, evaluating different variables, preventing direct comparison, especially with regard to the THPCS, whose number of publications was quite limited. Deficits were identified in the literature on the subject in Portuguese, with only one work on TPCS in Brazil, indicating the need for further studies.

The importance of developing more studies concerning the topic is highlighted, especially with methodologies that generate higher levels of evidence, such as prospective controlled studies, systematic reviews and meta-analyses. In addition, studies with a national target population are recommended, for a better analysis of the impacts of such a procedure in Brazil, making it possible to understand the specificities and profile of the Brazilian population. 


\section{CONCLUSION}

Vena cava-sparing TPCS is a technique to preserve the flow of the vena cava and portal system during liver transplantation. The studies developed on the subject point to benefits in hemodynamic stability, postoperative renal function and reduction of hospital stay.

It was not possible to conclude on the impact of the technique on hepatic ischemia-reperfusion injury or on the overall survival of the patient and the graft due to the relevant divergences in the literature. In living donor transplantation, THPCS can be used to prevent small-for-size syndrome, but due to the scarcity of data, it is still not possible to determine the subsequent need for shunt closure.

\section{AUTHORS CONTRIBUTION}

Substantive scientific and intellectual contributions to the study: Fonseca Neto OCL, Nascimento MEFM and Ribeiro LLPA; Conception and design: Fonseca Neto OCL and Nascimento MEFM; Analysis and interpretation of data: Nascimento MEFM and Ribeiro LLPA; Manuscript writing: Nascimento MEFM and Ribeiro LLPA; Final approval: Fonseca Neto OCL.

\section{DATA STATEMENT AVAILABILITY}

Not applicable.

\section{FUNDING}

Not applicable.

\section{ACKNOWLEDGEMENTS}

Not applicable.

\section{REFERENCES}

1. Pietersen LC, Sarton E, Alwayn I, Lam HD, Putter H, van Hoek B, et al. Impact of temporary portocaval shunting and initial arterial reperfusion in orthotopic liver transplantation. Liver Transpl. 2019;25(11):1690-9. https://doi.org/10.1002/lt.25592

2. Kim JD, Choi DL. Beneficial impact of temporary portocaval shunt in living-donor liver transplantation with a difficult total hepatectomy. Transplant Proc. 2015;47(3):694-9. https://doi.org/10.1016/j.transproceed.2014.12.036

3. Rayar M, Levi Sandri GB, Cusumano C, Locher C, Houssel-Debry P, Camus C, et al. Benefits of temporary portocaval shunt during orthotopic liver transplantation with vena cava preservation: a propensity score analysis. Liver Transpl. 2017;23(2):174-83. https://doi.org/10.1002/lt.24650

4. Calne RY, Williams R. Liver transplantation in man. I. Observations on technique and organization in five cases. Br Med J. 1968;4:535-40. https://doi.org/10.1136/bmj.4.5630.535

5. Nacif LS, Zanini LY, Sartori VF, Kim V, Rocha-Santos V, Andraus W, et al. Intraoperative surgical portosystemic shunt in liver transplantation: systematic review and meta-analysis. Ann Transplant. 2018;23:721-32. https://doi.org/10.12659/ AOT.911435

6. Addeo P, Locicero A, Faitot F, Bachellier P. Temporary right portocaval shunt during piggyback liver transplantation. World J Surg. 2019;43(10):2612-5. https://doi.org/10.1007/s00268-019-05042-7

7. Pratschke S, Rauch A, Albertsmeier M, Rentsch M, Kirschneck M, Andrassy J, et al. Temporary intraoperative porto-caval shunts in piggy-back liver transplantation reduce intraoperative blood loss and improve postoperative transaminases and renal function: a meta-analysis. World J Surg. 2016;40(12):2988-98. https://doi.org/10.1007/s00268-016-3656-1 
8. Belghiti J, Noun R, Sauvanet A. Temporary portocaval anastomosis with preservation of caval flow during orthotopic liver transplantation. Am J Surg. 1995;169(2):277-9. https://doi.org/10.1016/S0002-9610(99)80151-2

9. Faitot F, Addeo P, Besch C, Michard B, Oncioiu C, Ellero B, et al. Passive mesenterico-saphenous shunt: An alternative to portocaval anastomosis for tailored portal decompression during liver transplantation. Surgery. 2019;165(5):970-7. https:// doi.org/10.1016/j.surg.2018.10.036

10. Tzakis AG, Reyes J, Nour B, Marino IR, Todo S, Starzl TE. Temporary end to side portacaval shunt in orthotopic hepatic transplantation in humans. Surg Gynecol Obstet [Internet]. 1993 [cited 2021 May 23];176(2):180-2. Available from: https:// www.ncbi.nlm.nih.gov/pmc/articles/PMC2729161/

11. Botha JF, Langnas AN, Campos BD, Grant WJ, Freise CE, Ascher NL, et al. Left lobe adult-to-adult living donor liver transplantation: small grafts and hemiportocaval shunts in the prevention of small-for-size syndrome. Liver Transpl. 2010;16(5):649-57. https://doi.org/10.1002/lt.22043

12. Kinaci E, Kayaalp C. Portosystemic shunts for "too small-for-size syndrome" after liver transplantation: a systematic review. World J Surg. 2016;40(8):1932-40. https://doi.org/10.1007/s00268-016-3518-x

13. Goja S, Srivastava M, Singh M, Sinha R, Roy R, Mahabaleshwar V, et al. Is portal inflow modulation always necessary for successful utilization of small volume living donor liver grafts? Liver Transpl. 2020;26(2):304-5. https://doi.org/10.1002/ lt. 25670

14. Pratschke S, Meimarakis G, Bruns CJ, Kaspar M, Prix N, Zachoval R, et al. Temporary intraoperative porto-caval shunt: useless or beneficial in piggy back liver transplantation? Transpl Int. 2013;26(1):90-8. https://doi.org/10.1111/tri.12007

15. Ghinolfi D, Martí J, Rodríguez-Laiz G, Sturdevant M, Iyer K, Bassi D, et al. The beneficial impact of temporary porto-caval shunt in orthotopic liver transplantation: a single center analysis. Transpl Int. 2011;24(3):243-50. https://doi.org/10.1111/ j.1432-2277.2010.01168.x

16. Nacif LS, Zanini LY, Costa dos Santos JP, Pereira JM, Pinheiro RS, Rocha-Santos V, et al. Intraoperative temporary portocaval shunt in liver transplant. Transplant Proc. 2020;52(5):1314-7. https://doi.org/10.1016/j.transproceed.2020.02.074

17. Son YG, Byun SH, Kim JH. The anhepatic phase extended by temporary portocaval shunt does not affect anesthetic sensitivity and postoperative cognitive function: a case-control study. Medicine (Baltimore). 2016;95(49):e5654. https://doi. org/10.1097/MD.0000000000005654

18. Weniger M, Andrassy J, Weig T, Grabein B, Crispin A, Rentsch M, et al. Temporary intra-operative portocaval shunts, postoperative infections, and mid-term survival after cava-sparing liver transplantation. Surg Infect (Larchmt). 2017;18(7):8039. https://doi.org/10.1089/sur.2017.036 